Check for updates

Cite this: RSC Adv., 2019, 9, 4203

Received 30th November 2018 Accepted 21st January 2019

DOI: $10.1039 / \mathrm{c} 8 \mathrm{ra0} 9843 \mathrm{c}$

rsc.li/rsc-advances

\title{
Pore structure control of porous carbon obtained from phenol formaldehyde resin and ethylene glycol: the effect of $\mathrm{H}_{3} \mathrm{BO}_{3}$ on the pore structure
}

\author{
Xishi Wu, (D) ab Ronghua Su, ${ }^{c}$ Yunzhou Zhu*a and Zhengren Huang ${ }^{\star a}$
}

\begin{abstract}
Boric acid was used as a source of complexing agent to change phase separation kinetics and dynamics of the resin-glycol system to regulate the pore structure of porous carbon. The results show that the addition of $\mathrm{H}_{3} \mathrm{BO}_{3}$ in the resin mixtures can change the polymerization dynamics during curing of resin-glycol mixtures. For the complexation of $\mathrm{H}_{3} \mathrm{BO}_{3}$ to diols, the size of the ethylene glycol-rich phase produced during the curing of the resin mixture increase with the increase of the content of $\mathrm{H}_{3} \mathrm{BO}_{3}$. Similarly, the pore size of porous carbon after pyrolysis increases with the increase of $\mathrm{H}_{3} \mathrm{BO}_{3}$ content. The average pore size of resulting porous carbon can be regulated in the range from 15 to $2754 \mathrm{~nm}$. These results reveal that $\mathrm{H}_{3} \mathrm{BO}_{3}$ exhibited obvious effects in changing the pore structure of resin-glycol system during pyrolysis.
\end{abstract}

\section{Introduction}

As a carbon functional material with excellent pore structure, the porous carbon has excellent properties such as high porosity, good conductivity, controlled pore size and high specific surface area. ${ }^{1-3}$ So, it was widely employed in various fields, such as gas separation, water and air purification, adsorption materials, catalyst support, chromatography, supercapacitors and preparation of structural carbide ceramics. ${ }^{4-9}$ The application of porous carbon materials has a close relationship with its pore structure. For porous carbon in the field of supercapacitors, gas chromatography, etc., the pore size is required to be at the mesoporous size $(2-50 \mathrm{~nm})$. The novel macromolecular catalysts, conversion and separation materials, or porous carbons as preforms in the preparation of carbide ceramics, the pore size needs to be at the macrospore size $(>50 \mathrm{~nm})$. How to effectively control the pore structure of porous carbon is of great significance, especially in the field of preparation of carbide ceramics. Hucke ${ }^{\mathbf{1 0}}$ obtained a porous full carbon billet by high temperature cracking of high molecular polymer and obtained dense silicon carbide ceramic after siliconizing. Studies have shown that the pore structure of porous carbon has a great influence on the process of silicon infiltration, so it is necessary to precisely control the pore structure of porous carbon.

\footnotetext{
${ }^{a}$ State Key Laboratory of High Performance Ceramics and Superfine Microstructure, Shanghai Institute of Ceramics, Chinese Academy of Sciences, No. 588, HeShuo Road, Jiading District, Shanghai 201800, China. E-mail: zhrhuang@mail.sic.ac.cn; yunzhouzhu@mail.sic.ac.cn

${ }^{b}$ University of Chinese Academy of Sciences, Beijing 100039, China

${ }^{c}$ Suzhou Kunlun Heavy Equipment Manufacturing Co., Ltd, No. 599, Jinmao Road, Kunshan, Jiangsu 215313, China
}

At present, many methods have been used to prepare porous carbon materials such as hard/soft template method, ${ }^{\mathbf{1 1}, \mathbf{1 2}}$ activation method, ${ }^{9}$ and polymerization-induced phase separation (PIPS). ${ }^{13-18}$ In comparison, PIPS has a lot of advantages such as low manufacturing cost, simple technology process, and easy to industrialize. The process of PIPS is described as follows: the initial homogeneous solution of a non-reactive component (NRC) in reactive monomers (RM) will occur phase separation during polymerization of RM. After phase separation process, there are only polymerized RM-rich phase and an NRC-rich phase. The porous materials can be obtained by the removed of the NRC-rich phase and pyrolyzed of polymerized RM-rich phase to form frameworks. Thus the pore structure of resulting porous carbon can be controlled by changing phase separation reaction kinetics and dynamics. In order to control the pore structure and pore size of porous carbons, adequate research of the polymerization process is very necessary. At present, many researchers have reported the preparation of porous carbon with controlled pore structure based on the PIPS method. ${ }^{13-18}$ Wang $^{16}$ have systematically studied the effect of the process parameters on the pore structure of porous carbon which fabricated by finished sterol resin. $\mathrm{Xu}^{17}$ systematically investigated the effect of the ingredients of resin mixtures and the resin curing temperature on the pore structure of carbon monoliths which fabricated by phenol-formaldehyde resin (PF). The pore structure control of porous carbon is mainly related to the curing polymerization process of the organic resin. ${ }^{17}$ Zhang $\mathrm{Y} .^{13}$ and Yuan $\mathrm{Z}^{\mathbf{1 4 , 2 1}}$ have studied the effect of the resin system composition and curing agent on the pore structure of porous carbon. However, few studies addressed the possible relationship between the polymerization of the organic resin and pore structure of the carbonized product. 
Boric acid has rapidly developed into a thriving research area. ${ }^{18}$ The complexation of boric acid with diols and their congeners has shown great promise to develop novel aryl boroncontaining polymers with unusual properties, with borate linkages acting as inter-component bonds of supramolecular structures. ${ }^{19}$ Wang $^{20}$ introduced aryl-boron structure into PF to improve their heat resistance. In this paper, $\mathrm{H}_{3} \mathrm{BO}_{3}$ was used as a source of complexing agent to change phase separation reaction kinetics and dynamics of the resin-glycol system to achieve the pore structure control of porous carbon. Compared to the previous report, ${ }^{\mathbf{1 3 , 1 4 , 1 7 , 2 1}}$ our method is more effective. The addition of boric acid can achieve that the pore size of the resulting porous carbon material can be regulated in the range of $\mathrm{nm}$ to $\mu \mathrm{m}$. The effect of $\mathrm{H}_{3} \mathrm{BO}_{3}$ content on the pore structure of the porous carbons has been systematically investigated.

\section{Experimental procedures}

\subsection{Materials}

The chemicals used for the synthesis of porous carbon materials were $\mathrm{PF}$, ethyl alcohol (EG), $\mathrm{H}_{3} \mathrm{BO}_{3}$. $\mathrm{PF}$ (industrial level) were used as the carbon precursor. EG (AR, average molecular weight: 46.07) was employed as both the pore-forming agent and the solvent, and $\mathrm{H}_{3} \mathrm{BO}_{3}$ was used as the complexing agent.

\subsection{Preparation of precursor solutions and porous carbons}

The porous carbonaceous materials were synthesized by PIPS. The preparation process of porous carbons was shown in the following: PF, EG and $\mathrm{H}_{3} \mathrm{BO}_{3}$ were mixed by stirring mechanically at room temperature. Then the mixtures were poured into molds and successively held at $90{ }^{\circ} \mathrm{C}$ for $6 \mathrm{~h}$ for pre-curing. The rigid body was then post-cured to $200{ }^{\circ} \mathrm{C}$ from $90{ }^{\circ} \mathrm{C}$ and held for 8 h. Finally, the cured samples were carbonized under nitrogen atmosphere at $900{ }^{\circ} \mathrm{C}$ for $0.5 \mathrm{~h}$. Six samples were prepared, with mass content of $\mathrm{H}_{3} \mathrm{BO}_{3}$ varying from 0 to $5 \mathrm{wt} \%$, shown in Table 1 . And the resulting porous carbon were identified as B-0-B-5, accordingly. Each $\mathrm{H}_{3} \mathrm{BO}_{3}$ loading be performed in triplicate with the deviation on values represented in the data.

\subsection{Characterizations}

The apparent porosity, bulk density, average pore size and pore size distributions were measured by a mercury porosimetry (AutoPoreIV 9510, USA). The microstructure of the post-cured bodies and carbonized products were analyzed using a fieldemission scanning electron microscopy (FE-SEM; SU-8220,
Hitachi, Japan) equipped with a dispersive energy spectrum (EDS). The weight loss and pyrolysis behaviors of the resin mixtures during polymerization were examined using a thermogravimetric analyzer (TGA/SDTA85IE, Switzerland) under an inert atmosphere. Phase analysis of the carbonized products was conducted by X-ray diffraction (XRD; D/Max-2250V, Rigaku, Tokyo, Japan). Weight and volume changes of the samples after curing and pyrolysis were obtained by the change in weight and volume between pre-curing bodies and carbonized products. Fourier transform infrared spectrum (FT-IR) of the cured bodies were recorded in a range of $2000-400 \mathrm{~cm}^{-1}$ with a NICOLET Is10 (USA) FTIR by potassium bromide.

\section{Results and discussion}

\subsection{Interactions between resin mixtures and $\mathrm{H}_{3} \mathrm{BO}_{3}$}

3.1.1. Thermogravimetric analysis. The TG curves of the resin mixtures with and without $\mathrm{H}_{3} \mathrm{BO}_{3}$ during carbonization are shown in Fig. 1. It is found that the weight loss rate of the resin mixture without $\mathrm{H}_{3} \mathrm{BO}_{3}$ during carbonization has three distinct peaks. The first and second peak at about $99{ }^{\circ} \mathrm{C}$ and $175{ }^{\circ} \mathrm{C}$ is due to the evaporation of $\mathrm{H}_{2} \mathrm{O}$ and continuous EG, respectively. The third peak at about $300-600{ }^{\circ} \mathrm{C}$ is mainly due to the evaporation of dispersed EG and pyrolysis of cured resins. When $\mathrm{H}_{3} \mathrm{BO}_{3}$ is added, there is a significant change in the first peak and the second peak. The first peak, appearing at about $60{ }^{\circ} \mathrm{C}$, can be assigned to the reaction between hydroxymethyl phenol and $\mathrm{H}_{3} \mathrm{BO}_{3}$ to form some intermediates and water. As the $\mathrm{H}_{3} \mathrm{BO}_{3}$ content increases, the second peak shifts to a lower temperature point of $160{ }^{\circ} \mathrm{C}(\mathrm{B}-2), 155^{\circ} \mathrm{C}(\mathrm{B}-3)$, and $147^{\circ} \mathrm{C}(\mathrm{B}-4)$, respectively. It is mainly due to the increase in the size of the continuous ethylene glycol phase, making EG easier to evaporate. It can be known from the TG curve that as the $\mathrm{H}_{3} \mathrm{BO}_{3}$ content increases, the remaining weight of the resin mixture at $900{ }^{\circ} \mathrm{C}$ gradually increases. These results reveal that the resin mixtures get higher thermal stability when $\mathrm{H}_{3} \mathrm{BO}_{3}$ is added. ${ }^{20,22}$

According to $\mathrm{Xu},{ }^{17}$ continuous and dispersed EG-rich phases were both formed during phase separation, and the continuous EG-rich phase was nearly removed during curing, while the dispersed one was removed during pyrolysis. The weight and volume change of samples with different content of $\mathrm{H}_{3} \mathrm{BO}_{3}$ after pyrolysis are shown in Fig. 2.

It is clear that the remaining volume after carbonized with increasing the content of $\mathrm{H}_{3} \mathrm{BO}_{3}$, both show a trend of increasing first and then decreasing. It shows that the addition of $\mathrm{H}_{3} \mathrm{BO}_{3}$ leads to less volume shrinkage after pyrolysis when

Table 1 Effect of $\mathrm{H}_{3} \mathrm{BO}_{3}$ on the properties of porous carbons

\begin{tabular}{|c|c|c|c|c|c|}
\hline B-0 & 0 & $25.6 \pm 1.1$ & $15 \pm 5$ & $1.18 \pm 0.08$ & $0.21 \pm 0.07$ \\
\hline B-2 & 1.5 & $54.2 \pm 1.9$ & $642 \pm 15$ & $0.74 \pm 0.01$ & $0.77 \pm 0.02$ \\
\hline B-3 & 2.5 & $45.7 \pm 2.7$ & $1552 \pm 38$ & $0.79 \pm 0.03$ & $0.57 \pm 0.03$ \\
\hline B-4 & 3.5 & $42.5 \pm 1.3$ & $2363 \pm 54$ & $0.79 \pm 0.05$ & $0.53 \pm 0.05$ \\
\hline
\end{tabular}




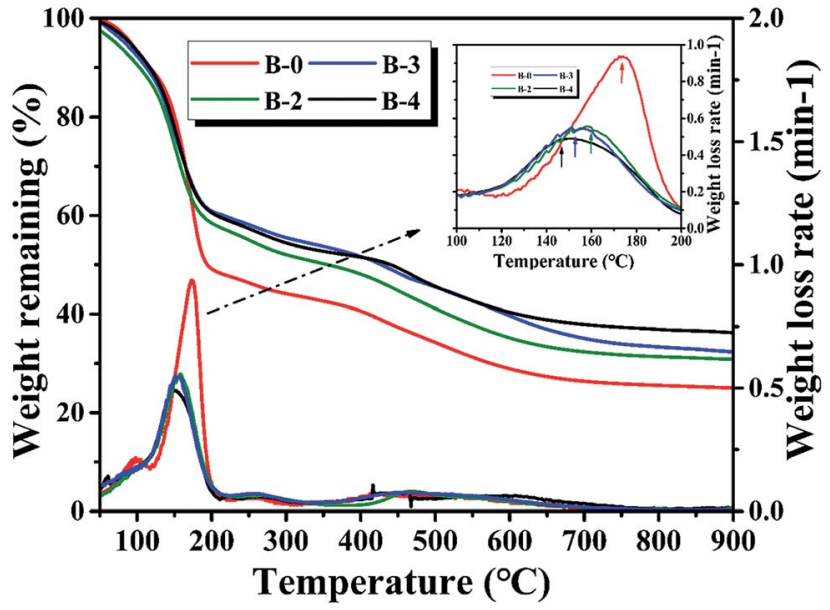

Fig. 1 Influence of $\mathrm{H}_{3} \mathrm{BO}_{3}$ on weight loss curves and weight loss rate curves.

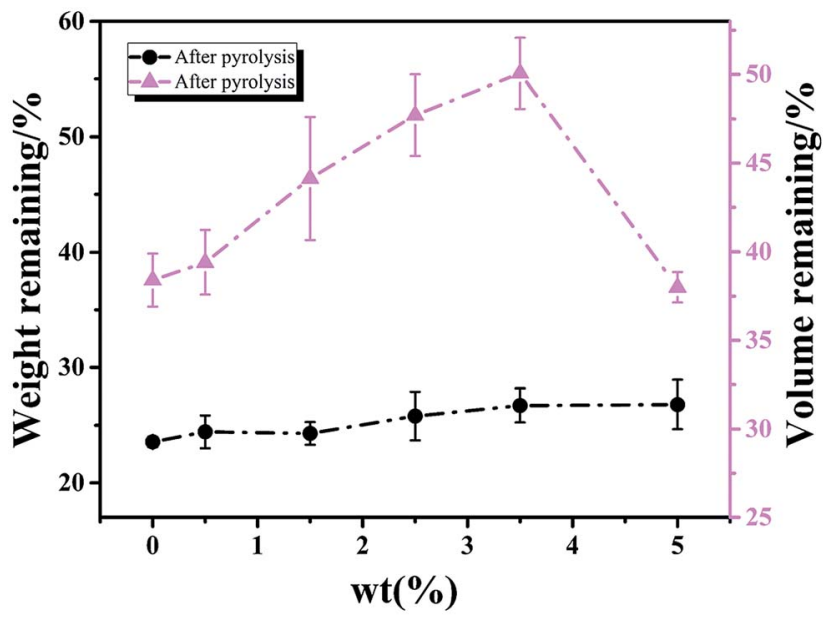

Fig. 2 The effect of $\mathrm{H}_{3} \mathrm{BO}_{3}$ on the weight and volume change of samples after curing and pyrolysis respectively.

the $\mathrm{H}_{3} \mathrm{BO}_{3}$ addition is less than $3.5 \mathrm{wt} \%$. The remaining weight after curing and remaining volume after carbonized begin to decrease when the $\mathrm{H}_{3} \mathrm{BO}_{3}$ addition is more than $3.5 \mathrm{wt} \%$. That is mainly because of the higher $\mathrm{H}_{3} \mathrm{BO}_{3}$ content, the higher viscosity of the resin mixture (shown in Fig. 3). During the mechanical stirring of the mixed resin mixture, the bubbles can be easy to be generated inside the high-viscosity resin solution and difficult to remove. The bubbles could remain during the curing process and be more likely to generate large bubbles during carbonization.

3.1.2. FT-IR spectra analysis. The FT-IR spectra of the resin mixtures with and without $\mathrm{H}_{3} \mathrm{BO}_{3}$ after curing are shown in Fig. 4. The absorption peaks at $1205 \mathrm{~cm}^{-1}$ and the multiple bands in the $880-756 \mathrm{~cm}^{-1}$ range were identified as resulting from $\mathrm{C}-\mathrm{O}$ bonds of phenol structures and $\mathrm{C}-\mathrm{H}$ flexural vibrations of the aromatic ring, respectively. The absorption peaks at $1270 \mathrm{~cm}^{-1}$ corresponded to the stretch vibrations of diphenyl ether linkages. Comparison of the spectra of samples with and

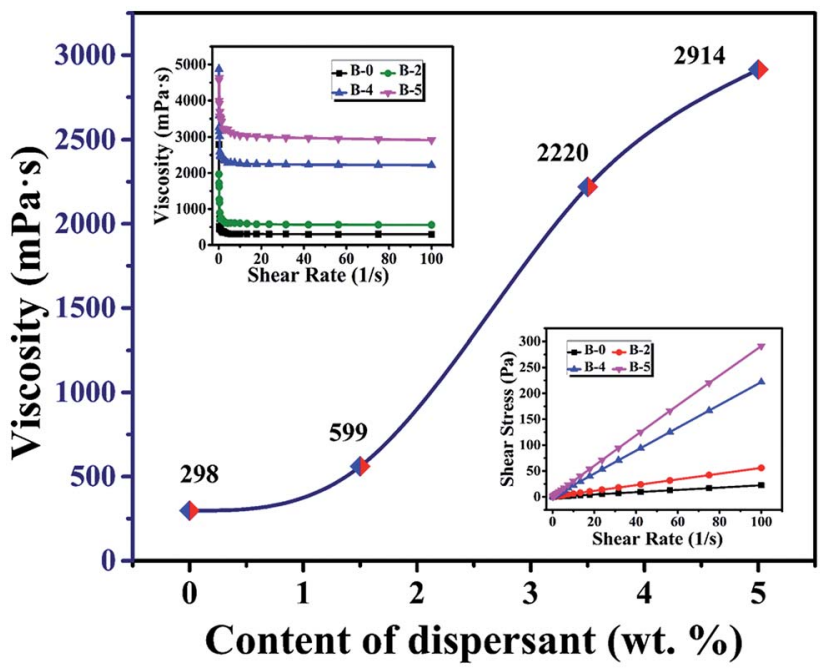

Fig. 3 The viscosity of the resin mixture with different $\mathrm{H}_{3} \mathrm{BO}_{3}$.

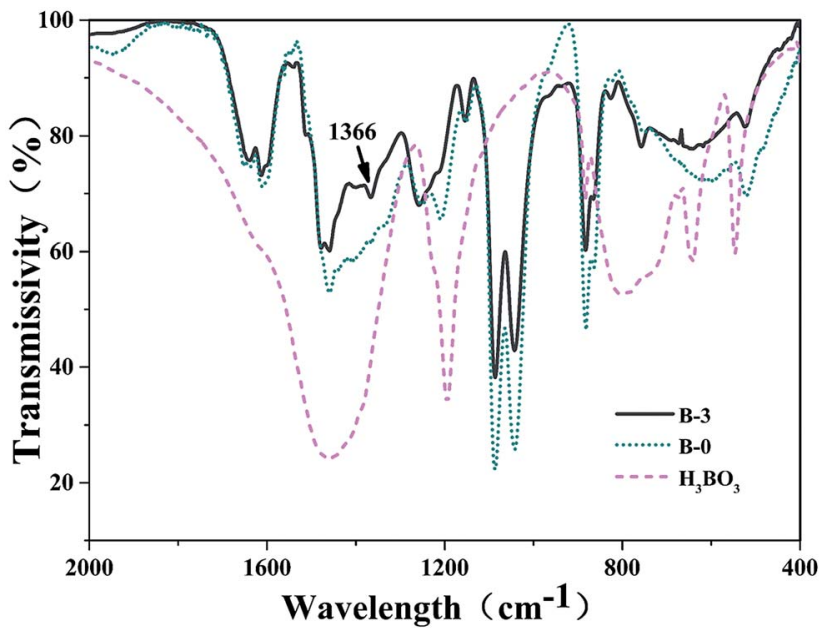

Fig. $4 \mathrm{FI}-\mathrm{IR}$ spectra of the cured bodies with different $\mathrm{H}_{3} \mathrm{BO}_{3}$.

without $\mathrm{H}_{3} \mathrm{BO}_{3}$ in Fig. 4 shows that there are two remarkable differences. An absorption peak appeared at about $1366 \mathrm{~cm}^{-1}$ after the addition of $\mathrm{H}_{3} \mathrm{BO}_{3}$, of which the absorption peak at $1366 \mathrm{~cm}^{-1}$ (ref. 23 and 24) attributed to the asymmetric B-O stretching vibrations. From the FTIR spectrum of the resin mixtures sample with $\mathrm{H}_{3} \mathrm{BO}_{3}$ (Fig. 4), the intensity of the $\mathrm{C}-\mathrm{O}$ stretching of phenolic $\mathrm{O}-\mathrm{H}$ at $1205 \mathrm{~cm}^{-1}$ decreases. The absorption peak near $1270 \mathrm{~cm}^{-1}$ does not change significantly before and after the addition of $\mathrm{H}_{3} \mathrm{BO}_{3}$ in Fig. 4, indicating $\mathrm{H}_{3} \mathrm{BO}_{3}$ can not reacted with phenylmethyl during curing of the resin mixtures.

On combining the above results, $\mathrm{H}_{3} \mathrm{BO}_{3}$ have participated in the curing reaction of the resin mixtures, and the phenylboronates are formed. The main process in which boric acid participates in the reaction is the reaction of phenolic hydroxyl groups with $\mathrm{B}-\mathrm{OH}$ to form $\mathrm{B}-\mathrm{O}-\mathrm{C}$ bonds. The possible reaction process is shown in Fig. 5 . This reaction process is beneficial to increase the degree of polymerization of the resin mixtures after 
curing and the length of the molecular chain of the resin monomer. Correspondingly, the size of the continuous EG phase produced during the polymerization phase separation becomes larger. That is expected to change the pore structure of resulting porous carbon.

\subsection{Characterization of the porous carbons}

The influence of $\mathrm{H}_{3} \mathrm{BO}_{3}$ in resin mixtures on the pore structure of resulting porous carbon is examined using the samples with the weight fraction of $\mathrm{H}_{3} \mathrm{BO}_{3}$ range from $0.5 \%$ to $5 \%$. Fig. 6 shows the SEM images of the microstructure of resulting porous carbon. It is evident that with the weight fraction of $\mathrm{H}_{3} \mathrm{BO}_{3}$ ranging from $0.5 \%$ to $5 \%$, the porous carbon network with interconnected pores can be obtained after carbonization. The formation of the porous structure is due to the removal of the ethylene glycol-rich phase in the resin mixtures during carbonization. Fig. 6 also shows the pore structure of the resulting porous carbon has significant differences. It can be seen from the image (Fig. 6) that the carbonized products obtained from resin mixtures with more $\mathrm{H}_{3} \mathrm{BO}_{3}$ content had a bigger pore size and thicker carbon skeleton. It can also be proved by mercury porosimetry, as shown in Fig. 9 and Table 1 .
The phase composition of resulting porous carbon was confirmed by XRD and EDS, as shown in Fig. 7. The results of the chemical composition analysis in the carbonized products (B-3) by EDS show that it is mainly carbon and a small amount of oxygen. The XRD results indicate that the main crystalline phase of the carbonized product is amorphous carbon. The reason why $\mathrm{B}_{2} \mathrm{O}_{3}$ is not observed is mainly due to the low melting point of $\mathrm{B}_{2} \mathrm{O}_{3}\left(450{ }^{\circ} \mathrm{C}\right)$. The low melting point of $\mathrm{B}_{2} \mathrm{O}_{3}$ led to an unavoidable the volatilization of $\mathrm{B}_{2} \mathrm{O}_{3}$ at high temperatures. ${ }^{20}$ The relatively low melting point of the involved oxides and the presence of open pore space favor a continuous evolution of liquid or gaseous oxides out of the material..$^{25}$

The microstructure of the cured bodies of resin mixtures before pyrolysis is shown in Fig. 8. It is obvious that there is no significant morphology difference in the samples before/after pyrolysis. The main reason is that the morphological of carbonized products basically was inherited from that of cured bodies. ${ }^{17,21}$ The formation of pores is derived from the volatilization of the ethylene glycol-rich phase. Fig. 8 also shows that pores obtained from resin mixtures with higher content of $\mathrm{H}_{3} \mathrm{BO}_{3}$ have a bigger pore size and thicker carbon skeleton. These results reveal that, due to the complexation of boronic acids to diols, the size of the ethylene glycol-rich phase increase
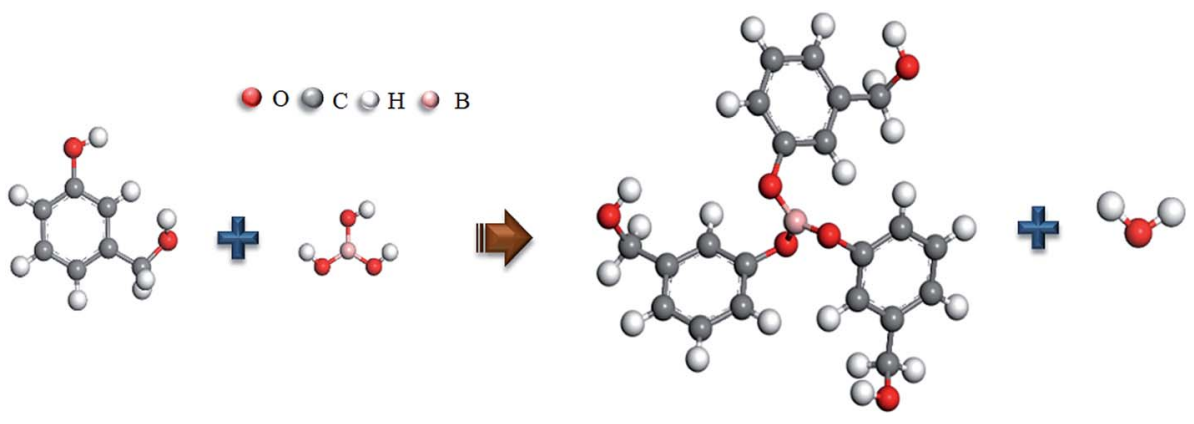

Fig. 5 The possible reaction processes.
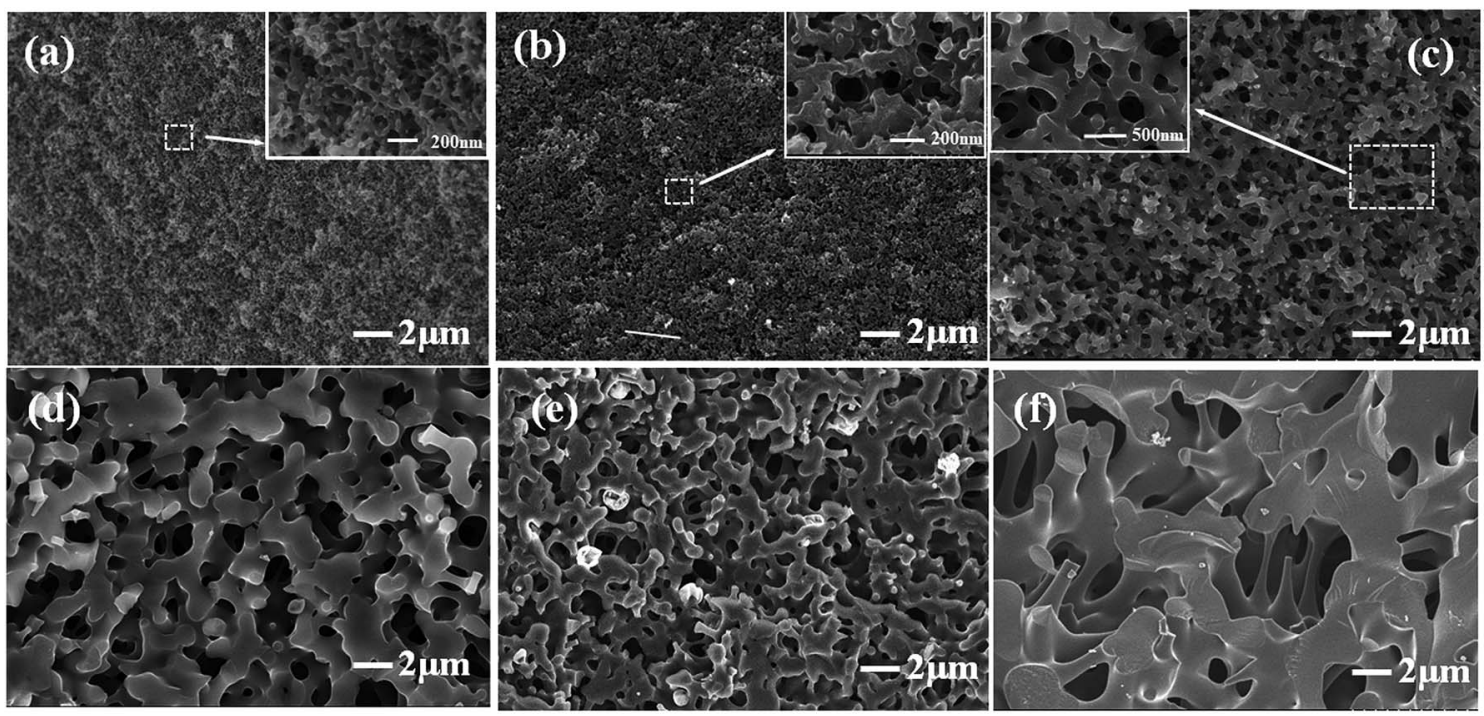

Fig. 6 Effect of $\mathrm{H}_{3} \mathrm{BO}_{3}$ on the morphologies of porous carbons. (a) B-0; (b) B-1; (c) B-2; (d) B-3; (e) B-4; (f) B-5. 


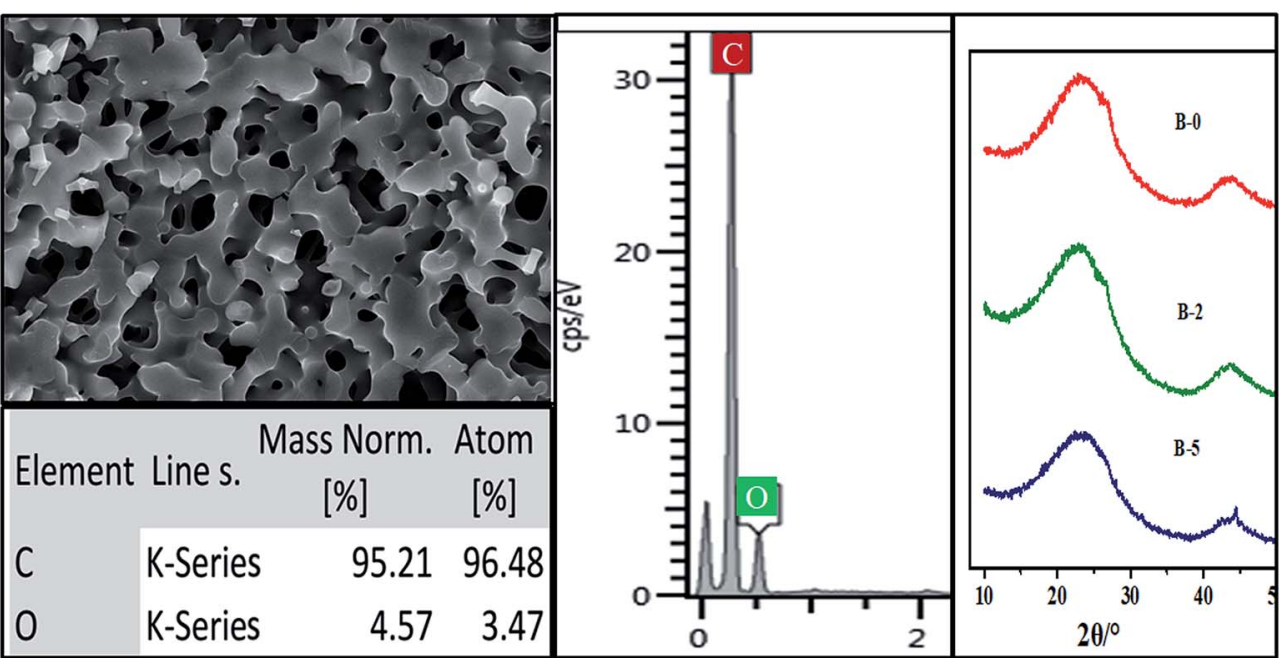

Fig. 7 The phase composition of resulting porous carbon of B-3.
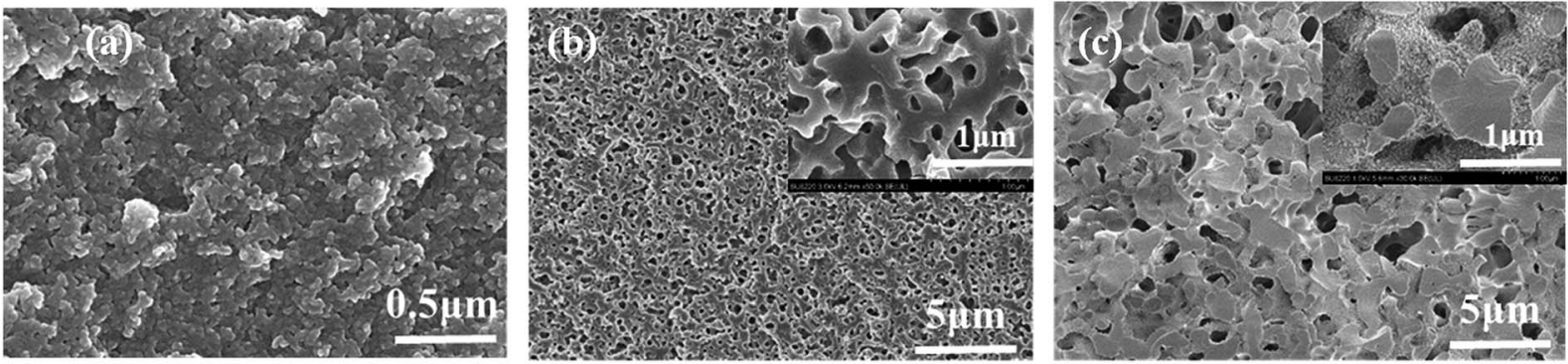

Fig. 8 The microstructure of the cured bodies of resin mixtures before pyrolysis. (a) B-0; (b) B-2; (c) B-3.

with the increasing content of $\mathrm{H}_{3} \mathrm{BO}_{3}$, which are consistent with the results of the thermogravimetric analysis.

Table 1 lists the properties of resulting porous carbon obtained from resin mixtures with different content of $\mathrm{H}_{3} \mathrm{BO}_{3}$. The average pore size of B-0 sample is $15 \pm 5 \mathrm{~nm}$. The reason of the pore formation can be explained as follows: the PF is completely miscible with ethylene glycol before curing. As the polycondensation reaction proceeds, the polymerized monomer gradually crosslinks into a bulk polymer, and the compatibility with ethylene glycol gradually decreases, which promotes phase separation. After curing and carbonization, the polymerized resin phase forms a carbon skeleton, and the ethylene glycolrich phase volatilizes at a certain temperature to form pores in the carbon skeleton, as is shown in Fig. 9(a). The average pore size of resulting porous carbon increased from $15 \pm 5$ to $2754 \pm$ $66 \mathrm{~nm}$ with the increase of $\mathrm{H}_{3} \mathrm{BO}_{3}$ content, which are consistent with the results of the SEM images. It can be obtained by FT-IR analysis of Fig. 4 that the addition of boric acid is advantageous for increasing the length of the monomer molecular chain of the resin mixture after curing. The increase in monomeric molecular chains provides the driving force generated by phase separation, facilitating the occurrence of phase separation, as is shown in Fig. 9(b). This facilitates the formation of a larger aperture. The pore size drastically changes between B-1 and B-2.
It indicates that the increase of the molecular chain contributes significantly to the phase separation. With increasing content of $\mathrm{H}_{3} \mathrm{BO}_{3}$ from $0 \%$ to $1.5 \%$, the apparent porosity of the resulting porous carbon increase from $25.6 \pm 1.1 \%$ to $54.2 \pm 1.9 \%$, while their bulk density decrease from $1.18 \pm 0.08$ to $0.74 \pm 0.01 \%$. However, when the $\mathrm{H}_{3} \mathrm{BO}_{3}$ addition is more than $1.5 \mathrm{wt} \%$, the apparent porosity after carbonized begins to decrease and the bulk density increase.

The pore size distribution results of porous carbon obtained from mercury porosimetry and $\mathrm{N}_{2}$ adsorption analysis are shown in Fig. 10. For samples without $\mathrm{H}_{3} \mathrm{BO}_{3}(\mathrm{~B}-0)$, the pore size distribution of resulting porous carbon was very narrow, with most of the pores distributing in the range from 10 to $30 \mathrm{~nm}$. It is also found that the pore size distributions of porous carbons become broader with the addition of $\mathrm{H}_{3} \mathrm{BO}_{3}$, shown in Fig. 10(a). When the content of $\mathrm{H}_{3} \mathrm{BO}_{3}$ was $5 \mathrm{wt} \%$, the pore size distribution of resulting porous carbon is in the range from 1500 to $3500 \mathrm{~nm}$, and some abnormal oversized pores appear in the sample. That is mainly because the high viscosity of the resin mixture (shown in Fig. 3) can be more likely to generate large bubbles during curing. As can be seen from Fig. 10(b), the resulting porous carbon sample has a micropore structure of about $4 \mathrm{~nm}$. The generation of micropore is attributed to the decomposition and devolution of boron species. 
(a)

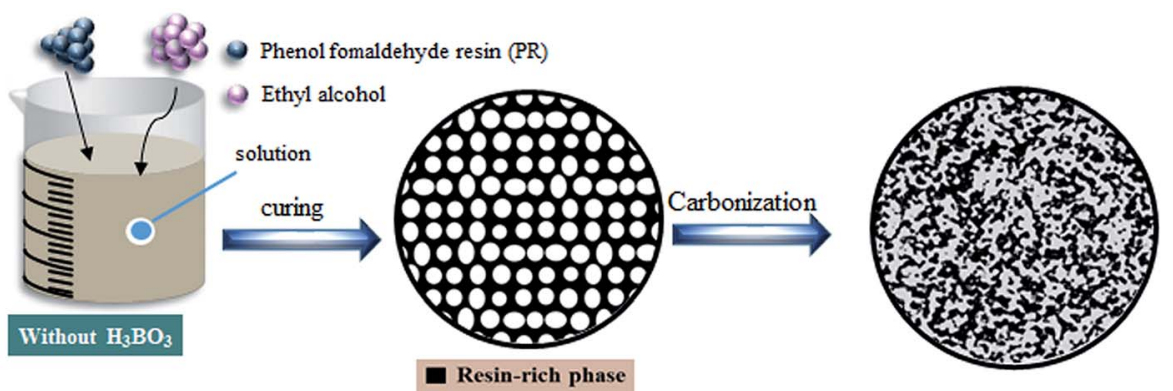

(b)
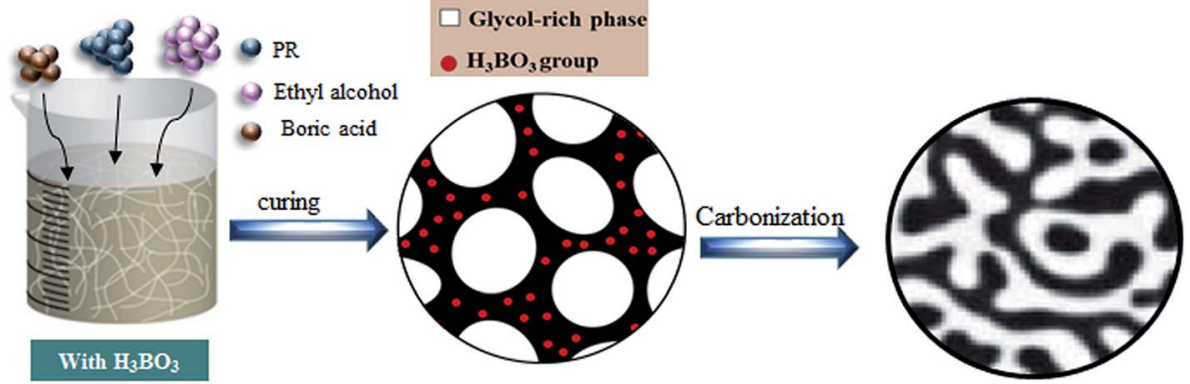

Fig. 9 The formation mechanism for the pore structure controlled carbons.
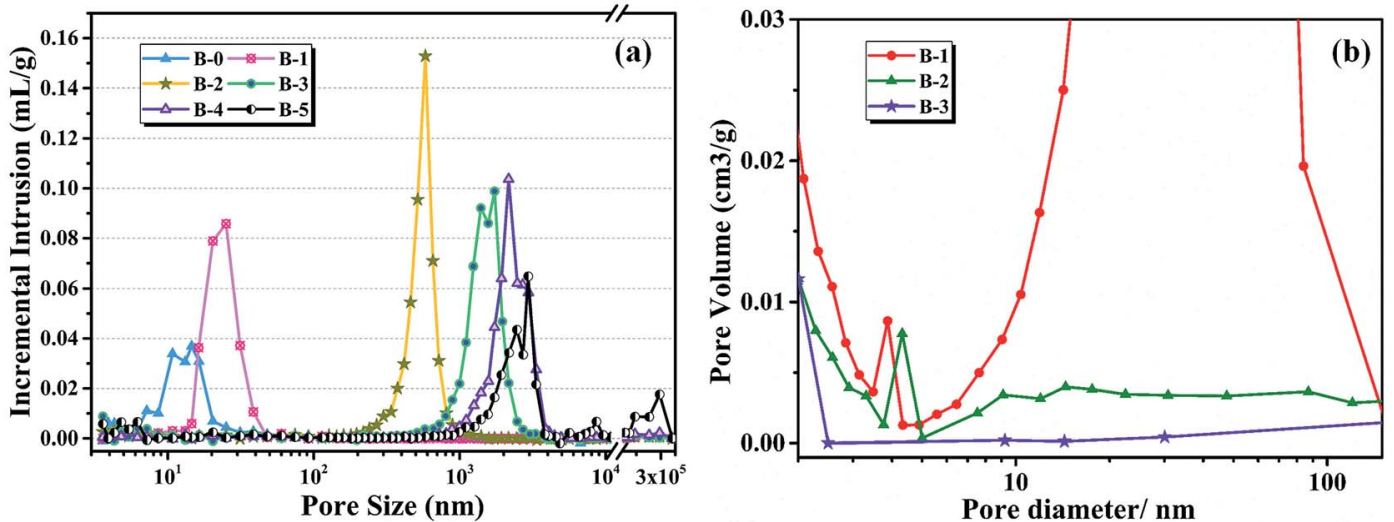

Fig. 10 Pore size distributions of different $\mathrm{H}_{3} \mathrm{BO}_{3}$ deduced from (a) mercury porosimetry, (b) $\mathrm{N}_{2}$ adsorption.

\section{Conclusions}

In conclusion, porous carbons with uniformly distributed pore structure are obtained by introducing $\mathrm{H}_{3} \mathrm{BO}_{3}$ to PR. The results show that the addition of $\mathrm{H}_{3} \mathrm{BO}_{3}$ in the resin mixtures can change the polymerization dynamics during curing of resinglycol mixtures. Because of the complexation of boronic acids to diols, the size of the ethylene glycol-rich phase produced during the curing of the resin mixture increase with the increase of the content of $\mathrm{H}_{3} \mathrm{BO}_{3}$. Similarly, the pore size of porous carbon after cracking increases with the increase of $\mathrm{H}_{3} \mathrm{BO}_{3}$ content. The average pore size of resulting porous carbon increased from $15 \pm 5$ to $2754 \pm 66 \mathrm{~nm}$ with the increase of $\mathrm{H}_{3} \mathrm{BO}_{3}$ content.

\section{Conflicts of interest}

There are no conflicts to declare.

\section{Acknowledgements}

This work was supported by Natural Science Foundation of Shanghai (No. 16ZR1440900), Shanghai Institute of Ceramics, Chinese Academy of Sciences and the State Key Laboratory of High-Performance Ceramics and Superfine Microstructures.

\section{References}

1 C. Chen, E. B. Kennel, A. H. Stiller, P. G. Stansberry and J. W. Zondlo, Carbon foam derived from various precursors, Carbon, 2006, 44, 1535-1543.

2 S. Han, K. Sohn and T. Hyeon, Fabrication of new nanoporous carbons through silica templates and their application to the adsorption of bulky dyes, Chem. Mater., 2000, 12, 3337-3341.

3 M. Ojima, S. Hiwatashi, H. Araki, A. Fujii, M. Ozaki and K. Yoshino, Appl. Phys. Lett., 2006, 88, $053103 \mathrm{e} 053106$. 
4 T. A. Centeno, J. A. Fernandez and F. Stoeckli, Correlation between heats of immersion and limiting capacitances in porous carbons, Carbon, 2008, 46(7), 1025-1030.

5 B. J. Kim, Y. S. Lee and S. J. Park, Novel porous carbons synthesized from polymeric precursors for hydrogen storage, Int. J. Hydrogen Energy, 2008, 33(9), 2254-2259.

6 A. Merritt, R. Rajagopalan and H. C. Foley, High performance nanoporous carbon membranes for air separation, Carbon, 2007, 45(6), 1267-1278.

7 H. F. Yang, Q. H. Shi, X. Y. Liu, S. H. Xie, D. C. Jiang, F. Q. Zhang, et al., Synthesis of ordered mesoporous carbon monoliths with bicontinuous cubic pore structure of Ia3d symmetry, Chem. Commun., 2002, 2(23), 2842-2843.

8 B. You, et al., Hydrogel-derived heteroatom-doped porous carbon networks for supercapacitor and electrocatalytic oxygen reduction, Carbon, 2016, 103, 9-15.

9 S. Han, et al., Metal-Phosphide-Containing Porous Carbons Derived from an Ionic-Polymer Framework and Applied as Highly Efficient Electrochemical Catalysts for Water Splitting, Adv. Funct. Mater., 2015, 25(25), 3899-3906.

10 E. E. Hucke, Methods of producing carbonaceous bodies and the products thereof, US Pat. 3859421, 1975.

11 Z. Hu, M. P. Srinivasan and Y. Ni, Adv. Mater., 2000, 12, 6265.

12 T. Y. Zhang, W. P. Walawender, L. T. Fan, M. Fan, D. Daugaard and R. C. Brown, Chem. Eng. J., 2004, 105(12), 53-59.

13 Y. Zhang, Z. Yuan and Y. Zhou, Effect of furfural alcohol/ phenol-formaldehyde resin mass ratio on the properties of porous carbon, Mater. Lett., 2013, 109, 124-126.

14 Z. Yuan, Y. Zhang and Y. Zhou, Effect of curing catalyst content on the pore structure of porous carbon obtained from phenolic resin and furfuryl alcohol, Mater. Lett., 2013, 110, 218-220.

15 P. K. Chan and A. D. Rey, Macromolecules, 1996, 29(27), 8934-8941.
16 Y. X. Wang, S. H. Tan, D. L. Jiang and X. Y. Zhang, Preparation of porous carbon derived from mixtures of furfuryl resin and glycol with controlled pore size distribution, Carbon, 2003, 41(11), 2065-2072.

17 S. Xu, J. Li, G. Qiao, H. Wang and T. Lu, Pore structure control of mesoporous carbon monoliths derived from mixtures of phenolic resin and ethylene glycol, Carbon, 2009, 47(8), 2103-2111.

18 T. Vergunst, F. Kapteijn and J. A. Moulijn, Preparation of carbon-coated monolithic supports, Carbon, 2002, 40(11), 1891-1902.

19 H. Kosonen, S. Valkama, A. Nykanen, M. Toivanen, G. Brinke, J. Ruokolainen, et al., Functional porous structures based on the pyrolysis of cured templates of block copolymer and phenolic resin, Adv. Mater., 2006, 18(2), 201-205.

20 S. Wang, Y. Wang, B. Cheng, Y. Zhong and X. Jing, The thermal stability and pyrolysis mechanism of boroncontaining phenolic resins: the effect of phenyl borates on the char formation, Appl. Surf. Sci., 2015, 331, 519-529.

21 Z. Yuan and Y. Zhang, Preparation and characterization of porous carbons obtained from mixtures of furfuryl alcohol and phenol-formaldehyde resin, Mater. Chem. Phys., 2014, 143, 707-712.

22 D. E. Garrett, Borates: Handbook of Deposits, Processing, Properties and Use, Academic Press, 1998.

$23 \mathrm{~J}$. A. Faniran and H. F. Shurvell, Infrared spectra of phenylboronic acid (normal and deuterated) and diphenyl phenylboronate, Can. J. Chem., 1968, 46(12), 2089-2095.

24 S. Wang, et al., High char yield of aryl boron-containing phenolic resins: the effect of phenylboronic acid on the thermal stability and carbonization of phenolic resins, Polym. Degrad. Stab., 2014, 99, 1-11.

25 Z. k. Chen, X. Xiong, G. d. Li and Y. l. Wang, Ablation behaviors of carbon/carbon composites with C-SiC-TaC multi-interlayers, Appl. Surf. Sci., 2009, 255, 9217-9223. 